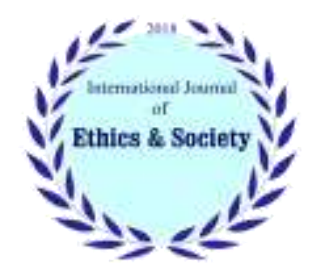

International Journal of Ethics \& Society (IJES)

Journal homepage: www.ijethics.com

Vol. 3, No. 4 (2022)

(Original article)

\title{
Social Components Affecting the Occurrence of Moral Gap
}

\author{
Manizheh Karami, Afsaneh Edrisi * \\ Dept. of Social Sciences, Faculty of Humanities, North Tehran Branch, Islamic Azad University, Tehran, Iran
}

\section{Abstract}

Background: Morality is one of the main components of the durability and consistency of human societies. Moral commitment is one of the determinants of social health. The degree of commitment of individuals in society to moral values can cause deviation or prevent social deviations in society. The present study aimed to study the social factors affecting the occurrence of moral gap.

Method: The method of this research is applied and descriptive-correlation survey. The statistical population included all citizens over 18 years in Abhar in 2020. The research samples were selected based on Morgan table and 411 people were selected by multi-stage cluster random sampling method. Data were collected using the Questionnaire Social Factors Affecting the Moral Gap. The content validity was measured by qualitative method and the reliability was measured by calculating Cronbach's alpha coefficient. The data were analyzed by SPSS software.

Results: The mean and standard deviation of the moral gap of citizens are 2.49 and 1, respectively. Pearson correlation coefficient test has a significant relationship between social factors and moral gap $(p=0.00, R=$ 0.219). Unfavorable social conditions increase the moral gap and, conversely, favorable conditions reduce the moral gap.

Conclusion: The results of this study indicate the effect of social components on the moral gap. Among the social components, the role of feelings of insecurity and feelings of injustice is directly acknowledged in the moral gap, so these results can help officials and managers to plan to reduce citizens' feelings of injustice and insecurity.

Keywords: Social factors, Moral gap, Inequality, Injustice, Insecurity

*Corresponding Author: Email: a_edrisi@iau-tnb.ac.ir

Received: 28 Jul 2021

Accepted: 19 Aug 2021

Copyright: (C 2022 Edrisi A. \& Karimi M. Published by Iranian Association of Ethics in Science and Technology This article is an open access article distributed under a Creative Commons Attribution-Noncommercial 4.0 International License. (https://creativecommons.org/licenses/by-nc/4.0/ ). 


\section{Introduction}

Ethics has been one of the main components of the permanence and consistency of human societies and one of the constant concerns of human societies. Concerns about the ups and downs of ethics and the degree of adherence to ethical principles have led to the formation of a large volume of writings on this component. All kinds of disorders and disorders in current and daily life show that in the field of morality, injuries and threats have occurred. The moral crisis in Iran has had dire consequences for this frontier, including forcing people to pay exorbitant costs for the small things in their lives (1). Based on the polls conducted, it can be stated that moral values are declining and the society is in a critical and anomic moral state and the general public has described Iranian society as an immoral society (2). Sociologists refer to pervasive disorder in societies as "anomie" or "moral crisis." Anomie is a lack of adherence to moral rules or normative weakness (3). Classical sociologists consider it a pathological and pathological condition that endangers the moral health of society (4). In the study of ethics, we can distinguish two levels of ethics; First level is the perceived level of morality or expected moral values, and second level is the experience level of moral practices and attributes.

Perceived level of morality is the level at which we have a perception of morality, goodness, and expected moral values. As long as there is truth, honesty, kindness, love, peace, friendship in the world. Experienced level of morality: This level is the morality that is experienced and lived. In the first level, man achieves morality, but in this level, he achieves morality. We all want morality, but then it's our turn to achieve morality. Iranian society is here to falter, and this goes back to institutional conditions (5). If we want to mention a characteristic of Iranian society based on field research, it may be that the distance between the two levels of perceived morality and lived morality is significantly higher, i.e. the gap between values and actions, without this being an inherent attribute of society (6). The debate over the gap between thought and action has a long history, and the roots of this debate can be traced to Socrates' moral views (7). Some sociologists believe that "moral requirements have a social origin" (8). In their view, the cause of the moral crisis is the unfairness of the rules governing behavior (9). In societies with greater inequality, comparing one's situation with others leads to anxiety, stress, and feelings of relative deprivation, and thus leads to social divisions among them (10). Sociologically, moral choices, in addition to subjectivity, are strongly influenced by the social environment in which individuals interact socially with others. Among these, the level of public trust in society and the social capital of individuals in general are of special importance (11). If there is no social justice, there will be no morality.

A certain environment causes people to lie and hypocrisy a lot. Insecurity alienates us from each other and as a result pessimism and slander (12). Feelings of inequality, weak social control, dissatisfaction and selfish individualism have had the greatest impact on the perception of moral crisis (13). During the Mongol conquest, moral values declined as the security of the people was endangered, and the issue of genuine culture and ethics fell to a second level (14). Feelings of political satisfaction, feelings of relative deprivation, feelings of moral deprivation, perception of social efficiency and social trust have a significant relationship with the tendency to morality (15). The results of studies show that bioethics and its underlying factors have been considered by many foreign and domestic researchers. In international surveys (16), Iranian data show that we love humanity more than other nations, but in practice we are not very committed to humanity. More than other nations, we have a spirit of convergence but self-determination, we want equality in values, but in practice we create hierarchy and inequality (5). Some studies show that there is a conflict between oral work ethic and practical work ethic (17). There is also a gap between the theoretical and behavioral levels of scientific ethics values (18). There is a large gap between real attitudes and behaviors in the field of information norms (19). Research findings show that our society suffers from the problem of lies in such a way that about $66 \%$ of people believe that most people are not 
trustworthy (20). The results of previous studies suggest that perceptions of social cohesion, trust, and interpretations of the values, norms, and morals of the people who make up the community lead to a breach of trust that conceals negative expectations and leads to feelings of insecurity. Given the importance of social ethics in promoting the health of society (23), social life is inconceivable without considering moral relations, so if we want to minimize social harms in society, we must inevitably take moral actions. (24) One of the most important factors of moral gap in human beings is society and social structures. In the present article, which has been written with a sociological approach, an attempt has been made to identify and explain the role of the institutional construction of social action in the occurrence of moral gaps. The question that arises here is why do actors take actions that conflict with the moral values they accept?

\section{Material \& Methods}

The research method is applied and descriptivecorrelation survey. The statistical population of the present study consists of all citizens over 18 years of age in 2020 in Abhar. The research samples were selected based on Morgan table and 411 people were selected by multi-stage cluster random sampling method. In this way, first the three districts of the municipality located in a specific city, then two constituencies (neighborhoods) were randomly selected from each district, and according to the size of the constituency, one to three blocks were selected from each constituency. After collecting Questionnaires, 411 questionnaires were used as the basis of research. Demographic characteristics of the sample are: The average age of the respondents was 35.2 years, $66.6 \%$ (274) were married, $33.4 \%$ (137) were single and 52.4\% (215) were male and 6/6.47\% (196) were female and the median income of households in the statistical population was about 20,000,000 Rials.

Data were collected through a researcher-made questionnaire. First, three concepts of moral value (honesty, altruism, and faithfulness to the covenant) were selected, which at the same time had a clear and unambiguous definition and were emphasized by most moral systems. Subsets were made for each of these indicators in the theoretical and practical aspects of ethics. The subscales of the theoretical ethics section were prepared by Likert method and the subsets of practical ethics were prepared based on projection and scenario-making techniques. The number of items in each of these sub-spectra is equal in both theoretical and practical parts. In total, each of the two dimensions of theoretical and practical ethics consists of 6 sub-spectra including 24 items in two dimensions. The highest score means observance of ethics and the lowest score indicates non-observance of ethics. The moral gap is the result of the difference between the theoretical and practical moral points of the individual. The closer the result of this difference is to zero, the more moral the individual is, and if the result is negative, it is a sign of non-observance of morality. Independent variables include feelings of insecurity, feelings of inequality, feelings of injustice, and trust at three levels (interpersonal, generalized, and institutional trust) with 54 Likert items that are tolerantly at the distance measurement level. Kolmogorov-Smirnov and Shapiro-Wilk tests were used to evaluate the normality of the variables. The variables of inequality, social trust and ethics in the practical dimension have a normal distribution at the level of $1 \%$ based on the Kolmogorov-Smirnov test. The variables of feeling of injustice, feeling of inequality, institutional trust in groups, social trust, ethics in theoretical dimension, ethics in practical dimension and moral gap have a normal distribution at $1 \%$ level according to Shapiro-Wilk test. The content validity of the questionnaire in the study of some researchers (19) was confirmed by 5 experts. Reliability on 291 students of Tehran University and Shahid Beheshti by calculating Cronbach's alpha coefficient was 0.861 in attitude and 0.839 in behavior. The content validity of the questionnaire of this research (29) was confirmed by 10 professors and experts. Reliability on 204 employees and clients of Mazandaran Social Cooperative and Social Welfare Organizations by calculating Cronbach's alpha coefficient in the verbal and ruling questionnaire was more than 0.70 . In the present study, the content validity of the questionnaire was confirmed by 15 faculty members. Cronbach's 
alpha coefficient was used to determine the reliability of the measuring instrument. The Cronbach's alpha value for all research concepts is greater than 0.70 . Thus, it can be said that the research has the necessary reliability or reliability. Confirmatory factor analysis method was used to determine the validity of the measuring instrument constructs. In addition, the questionnaires were first randomly distributed among 30 people and some of the questions in which ambiguities were found were modified. Therefore, it can be accepted that the questionnaire has a formal validity.

Table 1: Cronbach's alpha coefficient for re-
search variables
\begin{tabular}{|l|l|l|}
\hline $\begin{array}{l}\text { Variables Questions } \\
\text { Theoretical dimension of }\end{array}$ & 13 & 0.82 \\
\hline $\begin{array}{l}\text { morality } \\
\text { Practical dimension of } \\
\text { morality }\end{array}$ & 13 & 0.80 \\
\hline Social trust & 21 & 0.88 \\
\hline Feeling of inequality & 8 & 0.79 \\
\hline Feeling of insecurity & 7 & 0.72 \\
\hline Feeling of injustice & 7 & 0.88 \\
\hline
\end{tabular}

Data collection was performed in June 2020. First, the number of samples was determined by age and sex, and then the sample was completed in the reference plate in the blocks that were specified according to the map. The time to complete each questionnaire was 20 to 30 minutes. The method of data collection and collection was using interviews to complete the questionnaire and lasted for two weeks. The place of answer to the questionnaire was the sample house which was done in a sample of 411 citizens over 18 years old in Abhar city (by multi-stage cluster sampling method).

Parametric tests (Pearson correlation coefficient and regression) and descriptive statistics (mean standard deviation) were used to analyze the data. Data were analyzed using SPSS statistical software version 22. In this study, Kolmogorov-Smirnov test showed that the data are normal.

\section{Results}

The findings of this study include descriptive and inferential findings. Descriptive findings include some of the characteristics of the studied samples and inferential findings show the analysis of research variables.

\section{A) Descriptive features of the research sample}

The results of Table 2 show that more than $57 \%$ of the respondents were not bound by ethical issues in practice and more than 35\% stated that despite their practical adherence, they did not have a strong belief in these values. In total, it can be said that more than $88.5 \%$ of the respondents have a moral gap and only $7 \%$ have a moral balance. Respondents' scores tend to be negative overall. There was no gap in honesty in examining the moral value, which means that the respondents were honest in practice and opinion and had moral balance. More than $6.2 \%$ of the respondents are less altruistic in practice, and $21.7 \%$ of the respondents theoretically accept this moral value less.

Table 2. Distribution of respondents by moral gap score

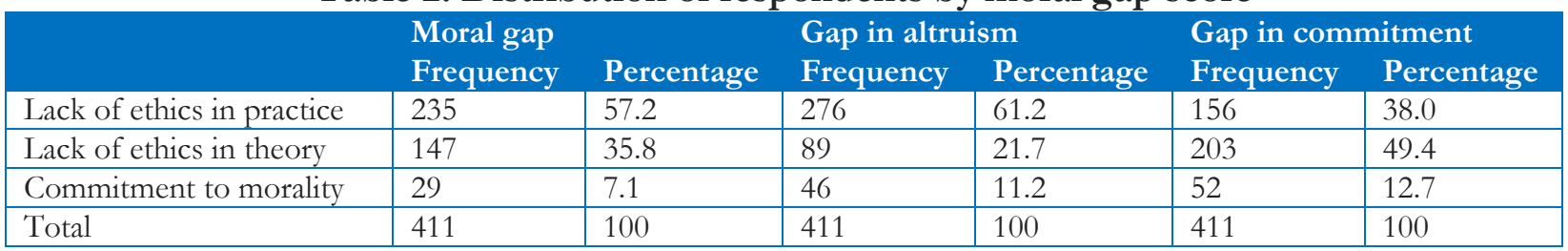

Therefore, it can be said that more than $82.9 \%$ of the respondents did not have the necessary moral balance and only $11.2 \%$ had a moral balance and were altruistic in practice and opinion. Respondents' scores also tend to be negative overall. The majority of respondents (49.4\%) do not believe in fulfilling the promise, and 38\% have observed less fulfillment of the promise. Therefore, it can be concluded that more than $87.4 \%$ of the respondents have a moral gap in terms of compliance with the covenant, and only $12.7 \%$ in practice and in terms of adherence to the covenant and had a moral balance. Due to the significant increase in 
disbelief in fulfilling the promise, the scores of the respondents also tend to be positive.

Table 3. Descriptive statistics related to the components of social factors and moral gap

\begin{tabular}{|c|c|c|c|c|c|}
\hline $\begin{array}{l}\text { Statistical } \\
\text { indicators }\end{array}$ & Moral gap & $\begin{array}{l}\text { Social factors } \\
\text { Injustice }\end{array}$ & inequality & insecurity & Social trust \\
\hline Mean & 2.49 & 25.51 & 20.52 & 22.19 & 9.54 \\
\hline SD & 1 & 4.32 & 4.32 & 6.04 & 58.0 \\
\hline
\end{tabular}

The mean and standard deviation of the moral gap of citizens are 2.49 and 1 , respectively.

\section{B) Inferential results}

Correlation coefficient and regression analysis were used to test the research hypotheses.

Table 4. Correlation coefficient between social factors and moral gap

Correlation coefficient $\quad$ Social factors

\begin{tabular}{|l|l|l|}
\hline \multirow{2}{*}{ Moral gap } & R & -0.219 \\
\cline { 2 - 3 } & P-value & 0.000 \\
\hline
\end{tabular}

The results of Table 4 showed that there is a significant relationship between social factors and moral gap ( $p=0.00, R=0.219)$. To answer the research hypotheses, first the correlation matrix between the research variables was used.

Table 5. Pearson correlation coefficient between moral gap and social factors components

\begin{tabular}{|c|c|c|c|c|c|}
\hline \multicolumn{5}{|c|}{ Correlation coefficient } & \multicolumn{5}{c|}{ Social factors } \\
\multirow{2}{*}{ Moral gap } & $\mathrm{R}$ & 0.133 & -0.106 & -0.173 & 0.085 \\
\cline { 2 - 6 } & P-value & 0.007 & 0.003 & 0.00 & 0.08 \\
\hline
\end{tabular}

Table 6. Regression coefficients related to the predicted model

\begin{tabular}{|l|l|l|l|l|l|l|l|l|}
\hline Model & $\begin{array}{l}\text { Non-standardized regres- } \\
\text { sion coefficient }\end{array}$ & $\begin{array}{l}\text { standardized regres- } \\
\text { sion coefficient }\end{array}$ & $\beta$ & \multicolumn{4}{|c|}{ p-value } & \multicolumn{3}{c|}{$\mathbf{R}^{2}$} \\
\hline Insecurity & -0.200 & 0.055 & -0.177 & -3.650 & 0.000 & & \\
\hline Injustice & -0.194 & 0.076 & -0.123 & -2.531 & 0.012 & 0.216 & 0.047 \\
\hline
\end{tabular}

Table 7: Table of standard coefficients and significance level for pattern paths

\begin{tabular}{|l|l|l|l|l|}
\multicolumn{2}{c}{$\begin{array}{l}\text { Path } \\
\text { to }\end{array}$} & \multicolumn{2}{l}{ Direct effect } & \multicolumn{2}{l|}{ Indirect effect } \\
\hline From & Moral gap & -0.17 & -- & 0.17 \\
\hline Insecurity & Moral gap & -- & 0.36 & 0.36 \\
\hline Inequality & Moral gap & 0.12 & 0.87 & 0.99 \\
\hline Social trust & Moral gap & -- & 0.58 & 0.58 \\
\hline
\end{tabular}

The results of Table 5 showed that the moral gap with social factors such as feelings of injustice $(\mathrm{P}$ $=0.007, \mathrm{R}=-0.133)$, feelings of inequality $(\mathrm{P}=$ $0.003, \mathrm{R}=-0.106)$, feelings of insecurity $(000 \mathrm{P}=$ $0.0, \mathrm{R}=0.173$ ) has a significant relationship.

In Table 6 of multiple regression analysis, the variables of feeling of injustice, feeling of inequality, feeling of insecurity as social factors and independent variables and the variable of moral gap as dependent variables have been used. The moral gap is explained by 0.2 by the variable of feeling insecure and 0.19 by the variable of feeling of injustice.

According to Table 7, the feeling of insecurity variable was only directly effective in the moral gap with a coefficient of 0.17 , and the variable of feeling of inequality was indirectly effective through the variable feeling of insecurity with a total of 0.36 in the moral gap. The variable of social trust has been indirectly effective in the moral gap 
through the two variables of feeling of inequality and feeling of insecurity by 0.58 . The variable of feeling of injustice has been indirectly effective in the moral gap through the other three variables by 0.98 and directly by 0.12 and in total by 0.99 .

\section{Discussion}

The first finding of the study showed that social components affect the moral gap. In other words, unfavorable social conditions increase the moral gap and vice versa, favorable social conditions reduce the moral gap. The results of the study showed that the moral gap among citizens is high. The findings of the three waves of the National Survey of Iranian Values and Attitudes show that moral values are declining and society is in a critical moral state and anomie (2). Some researchers have stated that; there is a significant difference between oral work ethic and practical work ethic (17-19) which is consistent with the research findings. Data analysis showed that social factors (feelings of injustice, feelings of insecurity and feelings of inequality) were significantly correlated with moral gap. That is, the less the sense of injustice, the inequality, and the sense of insecurity, and the greater the rule of law, the greater the adherence to one's theoretical and practical moral values. According to the cognitive view of ethics in sociology, it can be said that when a person interacts with his social environment, he witnesses various moral manifestations such as honesty, respect for others, self-sacrifice, seeking justice, helping the weak, protecting animals, etc. Has a moral interaction with members of the community. Conversely, in the immoral context of society, including high inequality, it weakens the emotional considerations that motivate people to promote the well-being of others as a moral duty. The researchers' findings showed that moral choices are strongly influenced by the social environment in which individuals interact socially with others (11). Conflicts of interest and the resulting moral dilemmas play a decisive role in immoral behavior (31). The results of expert research suggest that if there is no social justice, there will be no morality. A certain environment causes people to lie and hypocrisy a lot. Insecurity alienates us from each other and as a result pessimism and slander (12). According to the results of some researches (30) moral justice, moral atmosphere and positive emotion are important predictors of organizational citizenship behaviors and in order to improve these behaviors, it is necessary to pay attention to the development of moral justice, moral climate and positive emotion in organizations. The results of the research showed that paying more attention to commitment, organizational citizenship behavior and organizational justice, paying attention to attracting qualified people and employees with Islamic moral values is very important (32).

The results of some researchers showed that feelings of inequality, weak social control, dissatisfaction and selfish individualism had the greatest impact on the perception of moral crisis (13). The findings of some researches (20) are also in line with the results of this research. Research findings show that respondents feel they do not have equal access to valuable resources compared to others. This feeling arises from the fact that the actor realizes that there is a gap between what he considers worthy and what he can achieve. Therefore, they become indifferent to their moral responsibility to others. Feelings of inequality by undermining morality provide the basis for moral divisions and weakening morality. The results of international research (16) in Iran indicate hierarchy and inequality. The lower the inequality, the more moral the state of society. The study of some researchers showed that feelings of inequality, weak social control, dissatisfaction and selfish individualism had the greatest impact on the perception of moral crisis (13). According to Pearson correlation coefficient, there is a significant relationship between feelings of insecurity and moral gap. Therefore, it can be said that the respondents, when they feel insecure in society, have actions that go beyond the scope of ethics, which in some cases, these actions mean confronting the feeling of insecurity in society. The results of research by some researchers (21) showed that perceptions of social cohesion, trust and interpretations of values, norms and ethics of people in the community play a role in shaping the perception of risk and lead to 
feelings of insecurity. The findings of the researchers (14) showed that during the Mongol conquest, moral values declined to some extent as the security of the people was endangered and the foundations of social and individual life were shaken. The results of experts' research showed that insecurity causes our alienation from each other and as a result pessimism and slander (6), which is in line with the research results. The present study, like other studies, faced limitations that need to be considered in interpreting the results. Since the research sample included citizens living in the city of Abhar, so more caution is needed in generalizing the results. Another limitation of the research is the over-sensitivity of the subject of ethics. Due to the important role of ethics in the social health of society, other researchers are suggested to examine the ethical gap through empirical research by changing the components. Therefore, these results can help officials and stakeholders to plan to reduce the sense of injustice and insecurity of citizens, and in order to improve moral behavior, it is necessary to pay attention to the development of justice and equality, the atmosphere of security in society.

\section{Conclusion}

The study showed that there is a direct relationship between social factors and moral gap. The variable of feeling insecure has a direct effect on the moral gap and the variable of feeling injustice has directly or indirectly affected the moral gap through the other three variables. Among the social factors, the two variables of feeling insecure and feeling of injustice play a greater role in predicting the moral gap.

\section{Ethical Consideration}

After explaining the objectives of the study and reassuring the participants about the confidentiality of information and obtaining their oral consent, questionnaires were distributed among the participants.

\section{Conflict of Interest}

The authors declare that there is no conflict of interests.

\section{Acknowledgement}

All participants in this study are fully thanked and appreciated. This article is taken from the first written doctoral dissertation of the article and has the code of ethics committee number 15720505951010 from Islamic Azad University, North Tehran Branch.

\section{References}

1. Hajian E (2013). Sociology of Iranian Identity. ${ }^{\text {sted, Strategic }}$ Research Institute, Tehran. (In Persian).

2. Hajiani E (2014). Sociology of Ethics (Anabsis of the Social Status of Ethics in Iranian Society). 1sted, Publisher of Sociologists, Tehran. (In Persian).

3. Durkheim E, Leducation Morale, Lee Gary R, Robert W (1974). Religion, Socioeconomic Status, and Anomie. Jour nal of the scientific study of Religion, 13(1): 35-47. DOI: https://doi.org/10.2307/1384799

4. Durkheim E (2019). The Division of Social Work. Translated

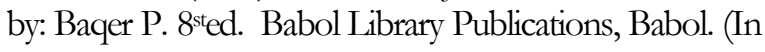
Persian).

5. Faraskhah M (2017). LessonsinEthical Discourses, Explaining Bioethics, Strategies and Tactics We Choose to Live, A Reflection on Two Levels of Ethics in Iranian Society. Session 18. University Publication, Tabriz. (In Persian).

6. Frastkhah M (2018). Iranians, Social Historical Background of

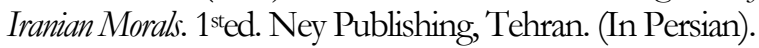

7. Baranjkar R (1996). The presence of the will in the principles of action (critique of the article assumptions of Islamic psychology). Quarterly Journal of the Prefecture and the University, 2 (6): 26-36. (In Persian).

8. Giddens A (2019). Durkheim. Translated by: Abazari Y. Kharazmi Publications, Tehran.

9. Durkheim E (2019). On the Division of Social Work. Translated by: Parham B. Markaz Publishing, Tehran. (In Persian).

10. Ebrahimi Loya A, Issa Maleki A (2017). Sociological study of factors affecting the weakening of social ethics. Journal of Behavioral Sciences Research and Studies, (28): 1-4. (In Persian).

11. Azkia M, Ghaffari Gh (2014). Sociology ofDevelopment. $11^{\text {sted. }}$ Kayhan, Tehran. (In Persian).

12. Frastkhah M (2018). Iranians, Social Historical Background of

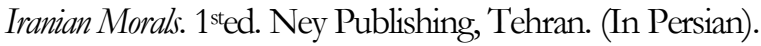
DOI: http://dx.doi.org/10.29252/ispi.11.1.35 
13. Bayat F, Mahdavi S M S, Sarookhani B (2020). Ethical crisis and the social factors affecting it (research in Tehran). Half-Yearly of Social Problems of Iran, 11 (1): 35-61. (In Persian).

14. Haji Marzdara M, Goya F, Mohammadi Badr N, Vazandi GR (2012). Historical study of the insecurities of the Mongol era and its role in moral decline. Quarterly Journal of the History of Iran and Islam, 2 (15): 55-68. (In Persian).

15. Webley S, Werner A (2008). Corporate codes of ethics: necessary but not sufficient, business Ethics. A Emopean Review, 17(4): 34.

16. GLOBE (2006). Research survey GLOBE project; Global leadership and organizational behavior effectiveness project. The GLOBE Foundation, USA.

17. Etebarian A, Salehi Zadeh S, Saeedi P (2010). The survey of the gap between existent work ethics and oral work ethics. Ethics in Science and Technology. 2014; 9 (2). (In Persian). DOR: 20.1001.1.22517634.1393.9.2.7.3

18. Khalafi Sh, Javadi Yeganeh M, Navabakhsh M (2017). Explaining the theoretical and behavioral values of scientific ethics among students. Quarterly Journal of Socio-Cultural Strategy, 24 (0): 109-141.

19. Jafari M B, Rezaian A, Shamsi F (2016). Ethical gap in the norms of information use. Ethics in Science and Technology, 11 (4): 59-20. (In Persian). DOR: 20.1001.1.22517634.1395.11.4.11.5

20. ISPA (2014). A Survey of the status of social etbics in Tebran.

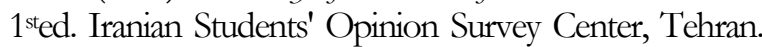
Pp.16 - 14. (In Persian).

21. Graham J, Meindl P, Koleva S, Iyer R, Johnson KM (2015). When values and behavior conflict: Moral pluralism and intrapersonal moral hypocrisy. Social and Personality Psychology Compass, 9(3): 158-170. DOI: https://doi.org/10.1111/spc3.12158

22. Sciolinio E (2000). Persian mirrors, The elusive face of Iran. The Free Press, USA. P.113.

23. Tavassoli Gh, Talebi A (2004). Conflict between social actions and moral values of adolescents. Al-Zahra Journal of Humanities, 14(50): 15-17. (In Persian).
24. Kahirdeh N (2018). Effective mental components in the emergence of moral social action from the perspective of Allameh Tabatabai. Bimonthy Quarterly of Allamah Tabatabai, 5 (8): 119-150.(In Persian).

25. Statistics Center of Iran (2019). General Census of Population and Housing. Planning and Budget Organization, Abhar/Iran. (In Persian).

26. Saee Arsi I (2014). Research methods in social sciences (Quantita-

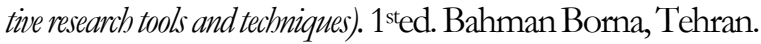
P. 22. (In Persian).

27. Augustine LF, Vazir S, Fernandez Rao S, Rao MV, Laxmaiah A, Ravinder P, Rao VV, Nair KM (2012). Psychometric validation of a knowledge questionnaire on micronutrients among adolescents and its relationship to micronutrient status of 15-19-year-old adolescent boys, Hyderabad, India. Public Health Nutr, 15 (7): 1182-9. DOI: https://dx.doi.org/10.3389\%2Ffpubh.2015.00277

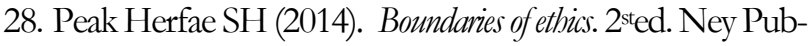
lications, Tehran. (In Persian).

29. Kia Kojori D, Ishaq Teymouri S (2014). Analysis of the gap between the dimensions of verbal work ethics and working ethics. Ethics in Science and Technology, 9(2): 1-8. (In Persian).

DOR: http://dorl.net/dor/20.1001.1.22517634.1393.9.2.7.3

30. Mahdad A, Boot shekan M, Malekzadeh Ahmadi M (2021). Predicting organizational citizenship behavior through perceptions of ethical justice, ethical climate, and positive affect. Ethics in Science and Tecbnology, 16 (1):159-163. (In Persian). DOR: http://dorl.net/dor/20.1001.1.22517634.1400.16.1.22.5

31. Hoseininasab H, Khodamipour A, Pourheidari O (2020). Conflict of interest and ethical dilemmas of independent auditors; situations and strategies. Int. J. Ethics Soc, 2 (3):1023. DOI: http://dx.doi.org/10.52547/ijethics.2.3.10

32. Jafarpour M, Mohammadi M (2020). Analyzing relationship between meritocracy and individual consequences in public organizations: the moderating role of Islamic ethics values. Int. J. Ethics Soc., 2 (2):55-61. DOI: http://ijethics.com/article-1-80-en.html 